\title{
LESS INVASIVE TECHNIQUES FOR MITRAL VALVE SURGERY
}

Didier F. Loulmet, MD

Alain Carpentier, MD, PhD

Peter W. Cho, MD

Alain Berrebi MD

Nicola d'Attellis, MD

Conal B. Austin, MD

Jean-Paul Couëtil, MD

Paul Lajos, MD
Objective: Minimally invasive surgical techniques aim at reducing the consequences of currently used large incisions, such as bleeding, pain, and risk of infection. Although this new approach developed rapidly in coronary surgery, it remains questionable in mitral valve surgery. This article reports the longest experience with minimally invasive mitral valve surgery, with particular attention to approach and techniques. Methods: From February 1996, the date of the first case of minimally invasive mitral valve reconstruction, to April 1997, 22 patients with a mean age of $54 \pm 2.7$ years were subjected to mitral valve surgery performed with less invasive techniques. Exposure of the mitral valve was achieved through a minithoracotomy $(n=12)$ or a ministernotomy $(n=10)$. Video assistance was used in all cases. Peripheral arterial cannulation $(n=21)$ and venous drainage $(n=22)$ were used in most cases. Results: In this series, valve surgery consisted in 19 repairs, two replacements, and one closure of a periprosthetic leak. In two cases it was necessary to convert to a larger incision. The average duration of cardiopulmonary bypass was $157 \pm 8.2$ minutes, ventilatory assistance $16 \pm \mathbf{4 . 6}$ hours, and intensive care unit stay $2.1 \pm 0.4$ days. Two patients required reoperation for bleeding and another for early recurrence of mitral valve regurgitation. There were no deaths and all patients were discharged with normal valve function. At most recent follow-up, all patients were in functional class I, with resumption of normal activity. Conclusion: Mitral valve surgery can be performed safely by means of less invasive techniques, but with increased technical difficulty. A low asymmetric median sternotomy seems preferable to an anterior thoracotomy. (J Thorac Cardiovasc Surg 1998;115:772-9)
C ardiac surgical procedures are among the most invasive and the most expensive of therapeutic techniques. During the past 5 years, attempts were made to apply less invasive techniques to reduce surgical trauma, pain, and cost. This new approach has radically changed the surgical management of certain lesions such as patent ductus arteriosus and atherosclerotic disease of the left anterior descending coronary artery. ${ }^{1-4}$ In February 1996, we ${ }^{5}$ performed the first complex mitral valve repair using a

From the Department of Cardiovascular Surgery and Organ Transplantation, Hôpital Broussais, University of Paris, Paris, France.

Received for publication May 13, 1997; revisions requested June 30, 1997; revisions received July 31, 1997; accepted for publication August 22, 1997.

Address for reprints: Didier F. Loulmet, MD, Department of Cardiovascular Surgery and Organ Transplantation, Hôpital Broussais, 96 rue Didot, 75014 Paris, France.

Copyright (C) 1998 by Mosby, Inc.

$0022-5223 / 98 \$ 5.00+0 \quad \mathbf{1 2} / \mathbf{1} / \mathbf{8 5 6 8 0}$ less invasive technique. Since then, 21 additional patients with mitral valve dysfunction have benefited from the same approach at our institution. In this report, we describe the evolution of our technique and the results obtained with particular emphasis on the difficulties encountered.

\section{Patients and methods}

From February 1996 to April 1997, 35 patients admitted to our institution for a mitral valve operation were offered the choice between the standard or the less invasive operation. Inclusion criteria were as follows: patients referred to the same surgeon, simple valve dysfunction, and young age. Twenty-two patients expressed a strong preference for a less invasive operation, mainly for cosmetic concern. Charts were reviewed retrospectively and follow-up was obtained for all the patients. Data are shown as mean \pm standard error of the mean.

Table I shows demographic data, and Table II lists the causes of mitral valve dysfunction. Two patients had preoperative percutaneous balloon dilatation for rheumatic mitral valve stenosis; one patient had residual stenosis and the other had mitral valve regurgitation 
Table I. Demographic data

\begin{tabular}{lc}
\hline & No. \\
\hline Age (yr) & $54 \pm 2.7$ \\
Gender & 4 \\
Men & 22 \\
Women & \\
NYHA class & 3 \\
I & 12 \\
II & 7 \\
III & 19 \\
Rhythm & 2 \\
Sinus & 1 \\
Atrial fibrillation & $68 \pm 2$ \\
AV block & \\
Ejection fraction $(\%)$ &
\end{tabular}

$N Y H A$, New York Heart Association; $A V$, atrioventricular.

caused by a tear in the anterior leaflet. Two other patients previously operated on in other hospitals had closed surgical commissurotomy with recurrence of stenosis and a mitral valve replacement with perivalvular leak. The preoperative echocardiographic characteristics of the mitral valve are shown in Table III.

Patient preparation and cardiopulmonary bypass. The patients were placed in the supine position. Standard hemodynamic monitoring and double-lung ventilation were used. External defibrillator pads were placed on the chest. As routinely used in our institution, electroencephalographic activity was recorded in all the patients. Intraoperative transesophageal echocardiographic examination was obtained for all the patients throughout the whole procedure.

Two different approaches to the mitral valve were used (Fig. 1). In the first 12 cases, the operation was carried out through a minithoracotomy of the anterolateral aspect of the fourth right intercostal space. In these cases, we used a submammary skin incision $(6$ to $7 \mathrm{~cm})$. In the 10 following cases, a ministernotomy was carried out through a $6 \mathrm{~cm}$ vertical midline skin incision. The midline sternotomy extended from the level of the second to the fifth intercostal space with two left horizontal branching incisions toward the second and the fifth intercostal spaces. The pleural cavities and the left mammary pedicle were kept intact.

In all cases, a video camera was used. When the left atrium was approached via a minithoracotomy, a thoracoscope was inserted through a port in the fourth intercostal space $(n=12)$. When the left atrium was approached via a ministernotomy, a thoracoscope was placed in the second intercostal space at the right lateral border of the sternum $(n=8)$. In the two last cases, a micro-camera was introduced through the sternotomy itself. The visualization system used in most cases $(n=20)$ was a 5 or $10 \mathrm{~mm}$ thoracoscope (0-degree or 30-degree view) connected to a three-chip Storz camera (Karl Storz $\mathrm{GmbH}$ and Co., Tuttlingen, Germany). In the two last cases, a flexible ministereo camera with a head-mounted display was used (Vista Cardiothoracic Surgery, Westborough, Mass.).

In most of the cases the arterial cannula was placed in the right femoral artery $(n=21)$. More recently $(n=1)$,
Table II. Causes of valve dysfunction

\begin{tabular}{lcc}
\hline \multicolumn{1}{c}{ Cause } & No. & $\%$ \\
\hline Degenerative & 8 & 36 \\
Rheumatic & 7 & 31 \\
Endocarditis & 3 & 14 \\
Congenital & 2 & 9 \\
Traumatic & 1 & 5 \\
Periprosthetic leak & 1 & 5 \\
\hline
\end{tabular}

Table III. Echocardiographic characteristics

\begin{tabular}{|c|c|c|}
\hline Lesions & No. & $\%$ \\
\hline Mitral stenosis & 6 & 27 \\
\hline Mitral regurgitation & 16 & 72 \\
\hline Type I & 1 & 5 \\
\hline Type II & 14 & 64 \\
\hline Type III & 7 & 31 \\
\hline
\end{tabular}

the arterial cannula has been placed directly in the ascending aorta. In the first 10 cases, we achieved venous drainage by double cannulation through the right femoral vein for the inferior venae cavae and the left femoral vein for the superior venae cavae using two 23F Bio-Medicus cannulas (Medtronic Bio-Medicus, Eden Prairie, Minn.). More recently, we developed a specially designed twostaged $23 \mathrm{~F}$ to $28 \mathrm{~F}$ flexible venous cannula (DLP, Inc., Grand Rapids, Mich.) placed in the right atrium via the right femoral vein by the Seldinger technique $(n=12)$. This cannula allowed a separate drainage of the superior and the inferior venae cavae and access to the right atrium whenever necessary (Fig. 2).

After the pericardial sac had been opened parallel to the phrenic nerve, a combined cardioplegia/suction cannula was placed in the ascending aorta. After the institution of extracorporeal circulation, ventilation was stopped and the venae cavae were surrounded by tapes and snared. A tape was also placed around the aorta before crossclamping. When a minithoracotomy approach was being used, the aorta was crossclamped with a transthoracic aortic crossclamp (Scanlan International, Inc., Minneapolis, Minn.) inserted through a port placed in the third intercostal space at the level of the midaxillary line, as described by Chitwood and coworkers. ${ }^{6}$ When a ministernotomy was being used, the aorta was crossclamped with a specially designed clamp (Delacroix-Chevalier, Paris, France) placed through the incision. In one case, we used the Heartport endovascular system (Heartport, Inc., Redwood City, Calif.). ${ }^{7}$ In most of the cases $(n=20)$, myocardial protection was achieved by intermittent cold blood cardioplegia and systemic hypothermia $\left(25^{\circ} \mathrm{C}\right)$. Myocardial temperature was monitored. In two cases, the operation was carried out on a fibrillating heart without crossclamping the aorta.

Surgical technique. A Tuffier retractor was used for thoracotomy and a specially designed mitral valve retractor (Delacroix-Chevalier) was used for ministernotomy. An intracardiac sump sucker was placed through the 


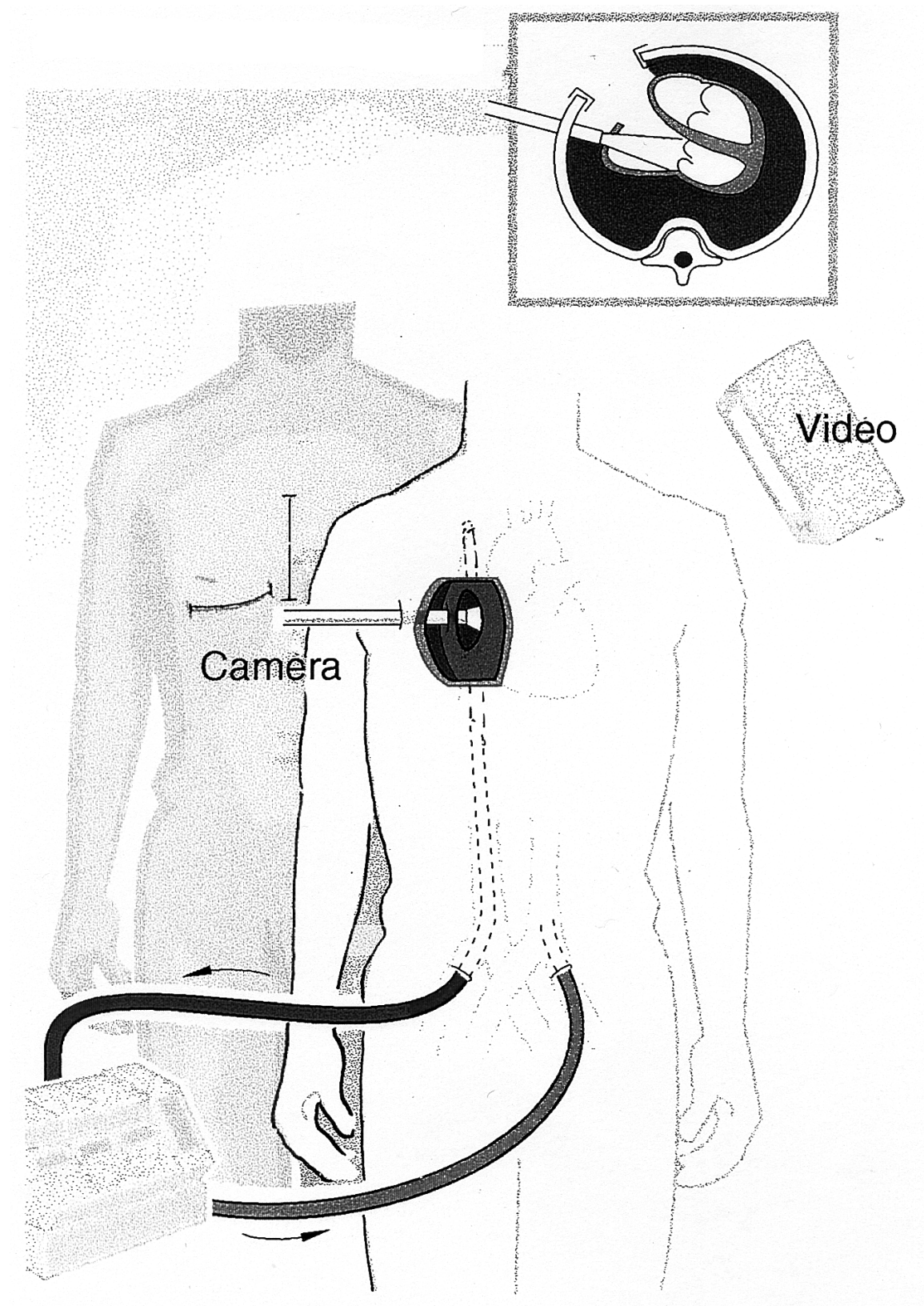

Fig. 1. The techniques used. The picture on the left shows the minithoracotomy, a $6 \mathrm{~cm}$ incision through the fourth right intercostal space (horizontal line), and the ministernotomy, a $6 \mathrm{~cm}$ midline incision from the second to the fifth intercostal space (vertical line). The picture on the right shows (1) the double-staged venous cannula introduced through the iliac vein, allowing drainage of both superior and inferior venae cavae, (2) the video assistance using a thoracoscope introduced into the left atrium, and (3) the view of the heart seen through a ministernotomy.

incision to keep the operative field dry. The mitral valve was approached through the roof of the left atrium after extensive dissection of the interatrial groove $(n=17)$ or by a transseptal incision through the right atrium $(n=5) .^{3}$
Mitral valve repair or replacement was performed with newly developed nondisposable instruments (DelacroixChevalier) (Fig. 3). Valve reconstructions were performed with the use of Carpentier's techniques and rings (Ed- 


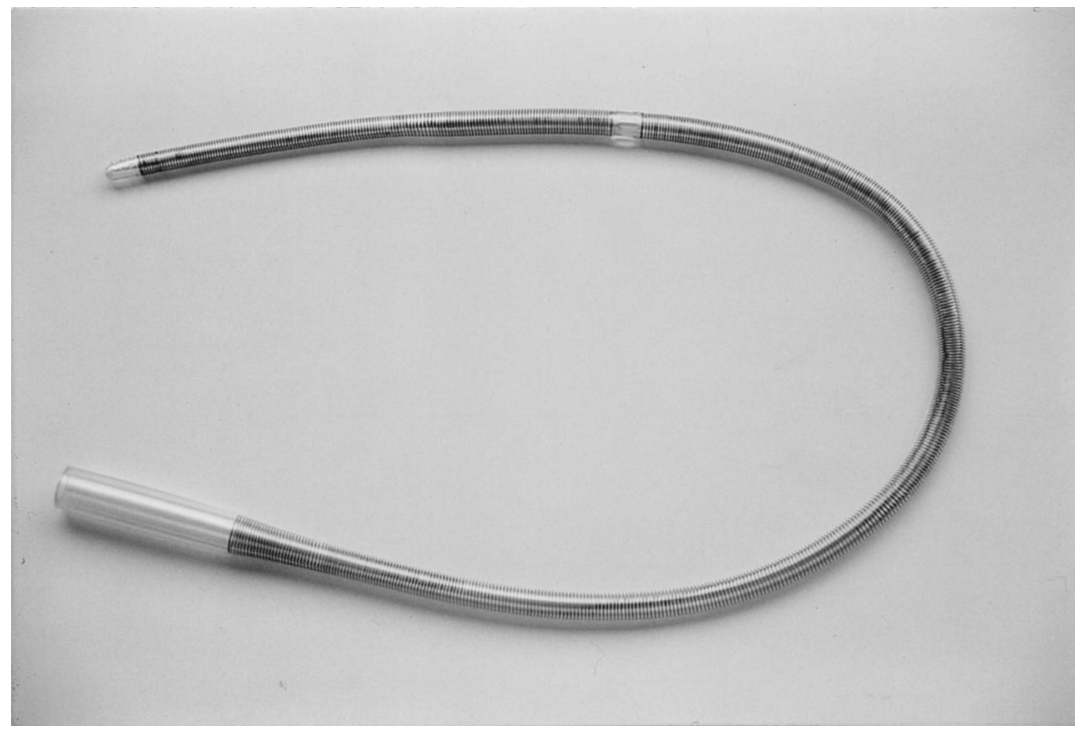

Fig. 2. The double-staged venous cannula used for separate drainage of the superior vena cava (distal holes) and the inferior vena cava (proximal holes).

wards CVS Division, Baxter Healthcare Corp., Irvine, Calif.). During the procedure, the surgeon had the choice between direct and indirect vision. The technique was completed under direct vision when satisfactory exposure of the mitral apparatus was obtained through the miniincision. In cases of limited visualization, the technique was directed by thoracoscopic secondary vision.

After the repair or replacement was completed, rewarming was started and the left atrium was closed with a transmitral cannula introduced into the left ventricle to keep the mitral valve incompetent. Deairing was achieved under transesophageal echocardiographic control before the aorta was unclamped in two steps: Retrograde deairing was accomplished through the suture line of the left atrium after removing the tapes around the venae cavae, filling the heart, and resuming ventilation; then antegrade deairing was accomplished by turning on the aortic suction line and shaking the left ventricle with a pediatric defibrillation paddle. After complete deairing was confirmed by transesophageal echocardiography, the aorta was unclamped. Defibrillation was carried out internally with the use of pediatric paddles or externally with the use of pads previously placed on the chest. Most often, when necessary, defibrillation was obtained with the external defibrillation pads while maintaining the lungs inflated and not collapsed to increase tissue conductivity. As soon as the heart started to beat and for the first subsequent beats, the aorta was intermittently clamped during systole and unclamped during diastole for further deairing through the aortic suction line. Weaning from cardiopulmonary bypass was achieved with transesophageal echocardiographic assessment of myocardial contractility and cavity filling.

Drainage was obtained by placing a single chest tube through the orifice of the camera when a minithoracotomy approach was used or by two Jackson-Pratt drains in the pericardium when the approach was made with a ministernotomy.

\section{Results}

Operative techniques are listed in Table IV. Two patients had valve replacement with preservation of the posterior leaflet. The patient who had a periprosthetic leak underwent reattachment of the mitral valve anulus to the prothesis by pledgetsupported interrupted sutures. All the other patients underwent mitral valve repairs by means of Carpentier's techniques. In one patient the mini-incision had to be converted to a larger incision to place regular-sized defibrillation paddles when defibrillation was found to be otherwise impossible. This patient had preoperative moderate aortic regurgitation that was not considered surgically significant and showed left ventricular distention when being weaned from bypass. He recovered uneventfully. In another patient the incision had to be converted to a median sternotomy without enlargement of the skin incision because of the impossibility of adequately exposing the mitral valve through a ministernotomy despite the use of the video camera. In one patient, brain dysfunction was detected by electroencephalography during deairing. The aorta was found to be incompletely crossclamped. Deairing was repeated and the arterial pressure was increased. Normalization of the electroencephalographic recording was obtained 10 minutes later. 


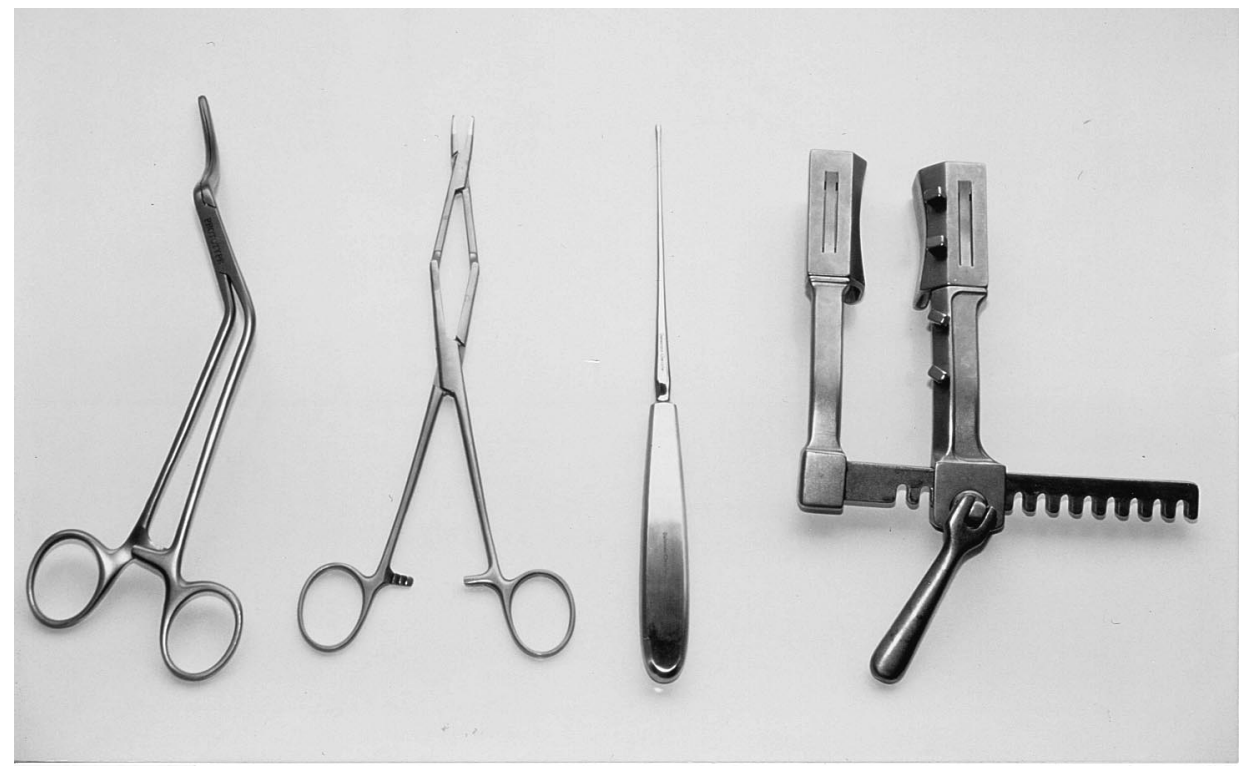

Fig. 3. Reusable instruments developed to perform minimally invasive mitral valve surgery. From left to right, aortic clamp, needle holder, knot pusher, and miniretractor.

This patient was placed in a hyperbaric chamber immediately after the operation. He recovered uneventfully. Since this case, and for all following cases, we have surrounded the aorta by tape to make sure to crossclamp the whole aorta. In 18 cases, myocardial function was assessed by transesophageal echocardiography and was unchanged compared with preoperative studies. Four patients required minimal inotropic support.

Table $\mathrm{V}$ shows the perioperative clinical course. There were no hospital deaths. One patient required mitral valve replacement after mitral valve repair because of early recurrence of mitral regurgitation demonstrated by transesophageal echocardiography in the intensive care unit. This patient had preoperative posterior leaflet prolapse resulting from the rupture of all the posterior chordae in the setting of bacterial endocarditis. Two patients required reoperation for bleeding. In all patients but three, ventilatory support lasted less than 1 day. Patients with minithoracotomy reported more perioperative pain than patients with ministernotomy and required more narcotic analgesic medication. One patient $(5 \%)$ had new postoperative atrial fibrillation compared with $18 \%$ in our patients undergoing conventional sternotomy. All the patients were discharged with excellent mitral valve and left ventricular function as assessed by echocardiography.
Every patient was followed up after the operation. There were no late deaths. All patients were in functional class I and resumed normal activities. As for esthetic results, the patients with minithoracotomy were more satisfied than those with ministernotomy.

\section{Discussion}

Many years after its introduction in gynecology, abdominal surgery, and thoracic surgery, minimally invasive techniques were applied to coronary artery surgery. ${ }^{8,9}$ Following this trend, we investigated the feasibility and potential benefit of minimally invasive techniques in valve surgery. The first complex mitral valve operation was carried out by our group in February $1996 .{ }^{5}$ Later on, several other groups began to investigate various types of minimally invasive approaches through a lateral thoracotomy, an upper midline sternotomy incision, or parasternal incision without video assistance or with video assistance. . $^{7,10-12}$ As our own experience grew, we tried to determine the best techniques and the best approach to allow complex mitral valve repairs to be performed with the same safety and efficacy as those provided by the currently used approach. From this experience, some answers can be given to the controversial questions raised by this operation.

Thoracotomy versus sternotomy. Large median sternotomy is the current approach in cardiac sur- 
Table IV. Operative techniques

\begin{tabular}{|c|c|c|}
\hline Techniques & $n$ & $\%$ \\
\hline Valve repair & 19 & 86 \\
\hline Annuloplasty & 17 & \\
\hline Resection posterior leaflet & 9 & \\
\hline Resection anterior leaflet & 2 & \\
\hline Sliding plasty & 2 & \\
\hline Commissurotomy & 4 & \\
\hline Papillary muscle splitting & 4 & \\
\hline Papillary muscle shortening & 1 & \\
\hline Chordal shortening & 2 & \\
\hline Chordal transfert & 2 & \\
\hline Valve replacement & 2 & 9 \\
\hline Periprosthetic leak closure & 1 & 5 \\
\hline
\end{tabular}

gery. It is not devoid of drawbacks for the patients (postoperative bleeding, wound infection, back pain, sternal dehiscence, and visible scar). The search for smaller incisions suited specifically for each different operation is therefore appropriate. Different authors have given different answers to the question: "What is the best minimally invasive approach to the mitral valve?" By using minithoracotomies and ministernotomies, we have found the quality of exposure of the mitral valve extremely variable, ranging from excellent to almost impossible. The spacial relationships between the different structures of the heart and the chest wall present a certain degree of variation from patient to patient. These variations are not significant for the surgeon when using large incisions. On the other hand, they determine the quality of the exposure through smaller incisions. On the basis of our experience, our preference today is for the ministernotomy incision described in this paper.

Direct versus video-assisted vision. The use of a mini-incision reduces the entry of light and the operative field, making the visualization more difficult for the surgeon and impossible for the assistant. A video camera was found useful in augmenting the illumination of the operative field and providing access to hidden structures, permitting the surgeon to compensate for a limited exposure and allowing the assistant to follow the operation. ${ }^{5,12}$ In our series, with growing experience, it was possible in certain cases to carry on simple techniques by watching only the monitor, but most often the successful repair of the mitral valve required direct vision. When the camera was placed in the left atrium, the two-dimensional view of the mitral valve on the monitor was excellent, but decreased depth perception compared with that provided by direct vision was a limiting factor for the realization of
Table V. Perioperative course

$\begin{array}{lc}\text { Pump time (min) } & 157 \pm 8 \\ \text { Crossclamp time (min) } & 82 \pm 10 \\ \text { Ventilation duration (hr) } & 16 \pm 4 \\ \text { ICU stay (days) } & 2.1 \pm 0.4 \\ \text { Hospital stay (days) } & 15.4 \pm 1.3 \\ \text { Chest tube drainage (ml) in the first } 24 \mathrm{hr} & 525 \pm 68 \\ \text { Patients requiring homologous blood (\%) } & 45 \\ \text { Patients requiring narcotic analgesic (\%) } & 50 \\ \text { New postoperative atrial fibrillation (\%) } & 5\end{array}$

complex techniques. When the camera was placed in the left ventricle, the view of the subvalvular apparatus was better than with direct vision and made easier the realization of simple techniques like splitting of papillary muscles or resection of secondary chordae. The development of three-dimensional surgical visualization systems may present a significant advantage for the cardiac surgeon. The threedimensional surgical images can be viewed on a head-mounted display. It has the advantage of offering normal stereo viewing but the disadvantage of creating possible visual-vestibular dissociation during head movements and of causing discomfort. Improvements can be excepted by miniaturization of the system. In the mean time, our preference is the use of a micro-camera mounted on a flexible tube that can be introduced within the heart through the midline incision.

Cardiopulmonary bypass: Central versus peripheral cannulation. Total exclusion of the heart from the circulation is mandatory for performing mitral valve reconstruction. This provides a bloodless field and prevents insidious rewarming of the myocardium. It is obtained in standard approaches by cannulation and snaring of both venae cavae. To that end, we developed a double-staged cannula that can be inserted in the right atrium via the femoral vein by the Seldinger technique. It presents two advantages: It occupies no space in the operative field while assuring good drainage even when the interatrial septum is retracted. Although the arterial cannula was placed in the femoral artery in most cases in our experience without complications, we recognize that this technique may have serious drawbacks: peripheral atherosclerosis may preclude cannulation, retrograde dissection or emboli may ensue, and other complications such as postoperative wound infection, hematoma, lymphocele, arteriovenous fistula, or stenosis of the femoral vessels may develop. For these reasons, in the last case, we placed the arterial cannula in the ascending aorta 
through the midline incision and the venous cannula in the femoral vein with a percutaneous technique. This approach proved to be efficient and we will continue to use it extensively.

Cold versus warm cardioplegia. Myocardial protection is crucial in reparative mitral valve surgery because crossclamp time may be long in cases involving complex lesions. When a mini-incision is used, the ventricles stay in direct contact with the surrounding structures and have the tendency to rewarm faster after cooling, a phenomenon confirmed by myocardial temperature monitoring. To reduce myocardial rewarming, our approach has been to maintain systemic temperature at $25^{\circ} \mathrm{C}$. On the other hand, systemic hypothermia made rewarming time longer. Normothermic blood cardioplegia could be a logical approach because it eliminates the problem of the thermal gradient between the myocardium and the surrounding structures. This technique of myocardial protection has shown excellent results for coronary artery surgery, but more information must be obtained concerning its application to valve surgery. ${ }^{13}$

Left atrial versus transseptal incision. The way the left atrium is entered seems to be a key point in improving the exposure of the mitral valve when mini-incisions are used. There are four principal ways of opening the left atrium: the incision of the roof of the left atrium after extensive dissection of the interatrial groove first described by Carpentier, the transseptal incision through the right atrium, the transverse biatrial transseptal incision, and the vertical biatrial transseptal incision. ${ }^{14-17}$ There appears to be an approach to the left atrium best suited for each type of mini-incision. In our experience, a minithoracotomy was best followed by a Carpentier approach, whereas a ministernotomy was best followed by a transseptal incision in the right atrium.

Deairing and defibrillation. When mini-incisions are used, deairing and defibrillation are made difficult because access to the ventricles is limited. For deairing, we have used our standard protocol described by Carpentier for mitral valve surgery, which has the feature of not requiring that the apex of the left ventricle be lifted. Air was removed from the left appendage by invagination of the appendage before closure of the left atrium. The process of deairing comprised two steps: the first involves deairing the left atrium through the atrial incision with no suction on the aortic line, and the second involves the deairing of the left ventricle by aortic suction with the aorta still clamped and the left atrium closed.
Complete deairing was demonstrated by transesophageal echocardiography before defibrillation and release of the aortic crossclamp. Most often, attempts to defibrillate the heart with the use of pediatric paddles was unsuccessful; we therefore recommend the placement of external defibrillation pads before placement of drapes. Assessment of contractility and filling of the heart during weaning from bypass, which is not possible under direct vision, benefited from the use of transesophageal echocardiography.

\section{Conclusion}

All the patients, but particularly the women, were extremely pleased with the cosmetic advantage of mini-incisions. As an average, patients with ministernotomy suffered less pain than patients with thoracotomy. Because of the different approaches used in this preliminary experience, it was not possible to draw valid conclusions with regard to blood loss or length of stay. These important data need further evaluation with precise indices. On the other hand, the increased difficulty of a mitral valve operation through a mini-incision should be strongly underlined. The danger is to perform suboptimal reconstructive operations. No compromise should be accepted in this regard and the surgeon should not hesitate to enlarge the incision if the approach compromises the quality of the operation.

\section{REFERENCES}

1. Benetti FJ, Ballester C. Use of thoracoscopy and a minimal thoracotomy, in mammary-coronary bypass to left anterior descending artery, without extracorporeal circulation: experience in 2 cases. J Cardiovasc Surg 1995;36:159-61.

2. Stevens JH, Burdon TA, Peters WS, Siegel LC, Pompili MF, Vierra MA, et al. Port-access coronary artery bypass grafting: a proposed surgical method. J Thorac Cardiovasc Surg 1996;111:567-73.

3. Laborde F, Noirhomme P, Karam J, Batisse A, Bourel P, Saint-Maurice O. A new video-assisted thoracoscopic surgical technique for interruption of patent ductus arteriosus in infants and children. J Thorac Cardiovasc Surg 1993;105:27880.

4. Burke RP, Wernovsky G, Van der Velde M, Hansen D, Castaneda A. Video-assisted thoracoscopic surgery for congenital heart disease. J Thorac Cardiovasc Surg 1995;109: 499-508.

5. Carpentier A, Loulmet D, Carpentier A, Le Bret E, Haugades B, Dassier P, et al. First open heart operation (mitral valvuloplasty) under videosurgery through a minithoracotomy. CR Acad Sci Paris Life 1996;319:221-5.

6. Chitwood RW, Elbeery JR, Chapman WH, Moran JM, Lust RL, Wooden WA, et al. Video-assisted minimally invasive mitral valve surgery: the "micro-mitral" operation. J Thorac Cardiovasc Surg 1997;113:413-4. 
7. Pompili MF, Stevens JH, Burdon TA, Siegel LC, Peters WS, Ribakove GH, et al. Port-access mitral valve replacement in dogs. J Thorac Cardiovasc Surg 1996;112:1268-74.

8. Bruhat MA, Manhes H. Essai de traitement per coelioscopique de la grossesse extra-utérine. Presse Med 1977; 6:2606.

9. Soper NJ, Brunt LM, Kerbl K. Laparoscopic general surgery. N Engl J Med 1994;330:409-19.

10. Koenertz W, Waldenberg F, Schutzler M, Ritter J, Liu J. Minimal access valve surgery through superior partial sternotomy: a preliminary study. J Heart Valve Dis 1996;5:63840.

11. Navia JL, Cosgrove DM. Minimally invasive mitral valve operations. Ann Thorac Surg 1996;62:1542-4.

12. Lin PJ, Chang CH, Chu JJ, Liu HP, Tsai FC, Chu PH, et al. Video-assisted mitral valve operations. Ann Thorac Surg 1996;61:1781-7.
13. Calafiore AM, Teodori G, Mezzetti A, Bosco G, Verna AM, Di Giammarco $\mathrm{G}$, et al. Intermittent antegrade warm blood cardioplegia. Ann Thorac Surg 1995;59:398-402.

14. Carpentier AF, Lessana A, Relland JYM, Belly E, Mihaileanu S, Berrebi AJ, et al. The "Physio-Ring": An advanced concept in mitral valve annuloplasty. Ann Thorac Surg 1995;60:1177-86.

15. Effler DB, Groves LK, Martinez WV, Kolff WJ. Open heart surgery for mitral insufficiency. J Thorac Surg 1958;36: 665-76.

16. Guiraudon GM, Ofiesh JG, Kaushik R. Extended vertical transatrial septal approach to the mitral valve. Ann Thorac Surg 1991;52:1058-62.

17. Dubost C, Guilmet D, de Parades B. Nouvelle technique d'ouverture de l'oreillette gauche en chirurgie à coeur ouvert: l'abord bi-auriculaire transseptal. Presse Med 1966;74: $1607-8$.

\section{Availability of Journal back issues}

As a service to our subscribers, copies of back issues of The Journal of Thoracic and Cardiovascular Surgery for the preceding 5 years are maintained and are available for purchase from Mosby at a cost of $\$ 16.00$ per issue until inventory is depleted. The following quantity discounts are available: $25 \%$ off on quantities of 12 to 23, and one third off on quantities of 24 or more. Please write to Mosby, Inc., Subscription Services, 11830 Westline Industrial Drive, St. Louis MO 63146-3318, or call 800-453-4351 or 314-453-4351 for information on availability of particular issues. If unavailable from the publisher, photocopies of complete issues may be purchased from UMI, 300 N. Zeeb Rd., Ann Arbor, MI 48106, 313-761-4700. 